\title{
ГЕОГРАФИЯ
}

И ГЕОИНФОРМАТИКА

DOI: https://doi.org/10.15688/nsr.jvolsu.2019.4.7

UDC 528.94:911.373

LBC 26.17

\section{CARTOGRAPHIC METHODS OF THE RESEARCH OF THE RURAL SETTLEMENT SYSTEM IN VOLGOGRAD REGION 1}

\author{
Natalya M. Khavanskaya \\ Volgograd State University, Volgograd, Russian Federation \\ Vladimir A. Alyaev \\ Volgograd State University, Volgograd, Russian Federation \\ Diana A. Semenova \\ Volgograd State University, Volgograd, Russian Federation
}

\begin{abstract}
The article presents the methodology of cartographic support of economic and geographical research of rural territories in Volgograd region. The methodological basis of the article is the theoretical foundations of classical economic geography and applied directions of geoinformation mapping. The authors consider the stages of the study, including: identification of mapped indicators; formation of an information base; compilation of thematic maps for each indicator; compilation of an integrated assessment card for a set of indicators. The following are proposed as the main mapped indicators: the number of rural population in $2010, \%$ by 1969 ; density of the rural population in 2010 , people $/ \mathrm{km}^{2}$; grouping of rural settlements by population, people; grouping of rural settlements by extrapolation tendency; conditions of the temporary transport accessibility of Volgograd; conditions of the temporary transport accessibility of the district center; natural fertility of agricultural lands in bonitet points. When constructing thematic maps, methods for classifying numerical fields are used, based on the calculation of the standard deviation: for maps of population dynamics, population density, and soil quality of agricultural land. Isoline mapping is used in the construction of maps of temporary transport accessibility, where the main methods of mapping are isochrones. To conduct a comprehensive assessment of the favorable resource potential of rural areas, the method of applying thematic maps is used, i.e. overlay operations. The methodology proposed by the authors as a whole allows the formation of an information database that includes information on the dynamics of the rural population in Volgograd region for individual $\approx$ villages, individual rural settlements, the density of the rural population in rural settlements, the conditions of transport accessibility of rural settlements, and the natural fertility of agricultural land in rural settlements, on the differences in resource potential in rural settlements.

Key words: cartographic methods, economic and geographical approach, potential for economic development, rural settlement system, Volgograd region.
\end{abstract}


УДК 528.94:911.373

ББК 26.17

\title{
КАРТОГРАФИЧЕСКИЕ МЕТОДЫ ИССЛЕДОВАНИЯ СИСТЕМЫ СЕЛЬСКОГО РАССЕЛЕНИЯ ВОЛГОГРАДСКОЙ ОБЛАСТИ ${ }^{1}$
}

\author{
Наталья Михайловна Хаванская \\ Волгоградский государственный университет, г. Волгоград, Российская Федерация \\ Владимир Алексеевич Аляев \\ Волгоградский государственный университет, г. Волгоград, Российская Федерация \\ Диана Александровна Семенова \\ Волгоградский государственный университет, г. Волгоград, Российская Федерация
}

\begin{abstract}
Аннотация. В статье представлена методика картографического обеспечения экономико-географического исследования сельских территорий Волгоградской области. Методологической базой служат теоретические основы классической экономической географии и прикладные направления геоинформационного картографирования. Рассмотрены этапы проведения исследования, включающие: выявление картографируемых показателей; формирование информационной базы; составление тематических карт по каждому показателю; составление интегральной оценочной карты по комплексу показателей. В качестве основных картографируемых показателей предложены: численность сельского населения в 2010 г. в \% к 1969 г.; плотность сельского населения в 2010 г., чел / км²; группировка сельских населенных пунктов по численности населения, чел; группировка сельских населенных пунктов по экстраполяционой тенденции; условия временной транспортной доступности г. Волгограда; условия временной транспортной доступности районного центра; естественное плодородие сельскохозяйственных угодий в баллах бонитета. При построении тематических карт используются методы классификации числовых полей, основанные на вычислении среднеквадратического отклонения: для карт динамики численности населения, плотности населения, бонитета почв сельскохозяйственных угодий. Изолинейное картографирование применяется при построении карт временной транспортной доступности, где главными способами картографирования являются изохроны. Для проведения комплексной оценки благоприятности ресурсного потенциала сельских территорий используется метод наложения тематических карт, то есть оверлейные операции. Предложенная авторами методика в целом позволяет сформировать информационную базу данных включающую сведения о динамике численности сельского населения Волгоградской области по отдельным селам, отдельным сельским поселениям, о плотности сельского населения по сельским поселениям, об условиях транспортной доступности сельских поселений, о естественном плодородии сельскохозяйственных угодий по сельским поселениям, о различиях ресурсного потенциала по сельским поселениям.
\end{abstract}

Ключевые слова: картографические методы, экономико-географический подход, потенциал экономического развития, система сельского расселения, Волгоградская область.

Введение. Проблемы исследования сельского расселения относятся к числу основополагающих, оказывающих влияние на многие аспекты общественного развития. В современной мировой экономико-географической науке доминируют исследования, отражающие классические методологические подходы $[7 ; 9 ; 14 ; 18]$. К числу известных (переведенных на русский язык) зарубежных работ по проблемам расселения необходимо отнести работу Голда Дж. [8]. В ней отмечается, что расселение населения отражает длительное доминирование определенных ценно- стей, отражающих постоянное влияние внешних воздействий на личные эмоции, первичные эмоциональные реакции, поведенческие реакции. При этом признается, что важнейшей поведенческой реакцией человека является оценка притягательности территории с позиций обеспечения условий жизнедеятельности, прежде всего базирующихся на природной основе (обеспеченность водой, степень естественного плодородия почв). По мере возрастания экономического потенциала на первый план выходят индивидуальные потребности человека в той или иной территории. 
В современной экономической системе расселение на сельских территориях занимает определенное место в иерархии экономических приоритетов.

При проведении территориальных исследований актуальным являются методологические основы, сформированные на основе использования работы Тойна П., Ньюби П. [13]. При изучении экономико-географических проблем расселения значительное внимание уделяется формированию общей логики исследования, которая складывается из характеристики разнообразных методов сбора информации, методов статистической обработки данных, методов наглядного представления данных, методов исследования размещения. При сборе информации, касающейся расселения населения, необходимо обратить внимание на статистические публикации, выпускаемые официальными органами государственной статистики. Важное значение имеют опубликованные карты, являющиеся источником разнообразной экономико-географической информации. Значительно усиливают актуальность исследования статистические данные, опубликованные в прошлые десятилетия. Экономико-географическое исследование выигрывает от использования архивных данных.

Важное значение для экономико-географического исследования имеют методы геоинформационного картографирования $[10 ; 11$; $12 ; 15]$ и сетевого анализа размещения сельских населенных пунктов [19; 20;21]. Их сущность заключается не только в визуализации системы сельского расселения, но, главное, в выявлении и анализе факторов расселения, динамики его пространственно-временной организации.

Одним из способов картографической визуализации, широко применяемой в экономико-географических исследованиях, являются хорохроматические карты, при разработке которых требуется выделение групп с равным интервалом изменений значения. На их основе можно разработать легенду карты плотности сельского населения. При исследовании расселения большое значение имеет выявление сходства и различий в размещении объектов. Через карты изохрон можно отражать условия временной транспортной доступности.
В современной отечественной экономической географии при изучении сельского расселения используются основные положения экономико- географической концепции единой системы расселения, разработанной экономико-географами МГУ, прежде всего Хоревым Б.С. $[16 ; 17]$. На ее основе была разработана общегосударственная программа «Генеральная схема расселения» страны, а в Волгоградской области единая система расселения была основой «Схемы районной планировки Волгоградской области» (1978 г.).

Отличительной особенностью исследований сельского расселения в последние годы является опора на положения единой системы расселения в сочетании с использованием информатизации при проведении расчетов и оформлении карт. Преобладают работы на уровне сельских административных районов, так как именно на этом уровне официально публикуются статистические данные [5; 6].

Объект и методы исследований. Исследование является неотъемлемой частью тематического направления, посвященного территориальной организации хозяйства Волгоградской области, разрабатываемого авторами ранее [1-4]. В рамках предложенной работы главной целью является формирование методики картографического обеспечения экономико-географического исследования сельских территорий.

Проведение исследования охватывает несколько этапов. Первый этаn - подготовительный. В задачи этого этапа входит выявление картографируемых показателей, позволяющих оценить благоприятность существующей системы сельского расселения. Выбор показателей основан на таких фундаментальных основах как, Ф3 «О стратегическом планировании в Российской Федерации», «Стратегия пространственного развития Российской Федерации до 2025 года» и «Стратегия устойчивого развития сельских территорий в Российской Федерации на период до 2030 года». Из этих документов следует, что размещение хозяйства на территориальном уровне сел и сельских поселений зависит от наличия ресурсов общего пользования, к которым относятся:

1. Численность населения, плотность населения, отражающие потенциал живого труда. 
2. Условия транспортной доступности, которое учитывается при развитии всех видов хозяйственной деятельности.

3. Естественное плодородие сельскохозяйственных земель как ресурс для развития аграрного производства, служащего источником средств существования населения.

Второй этап включает в себя составление информационной базы исследования. Методика работы по формированию информационной базы определяется необходимостью строгой временной и территориальной упорядоченностью. Работа с фондами ГАВО (Государственного архива Волгоградской области) включает в себя изучение каталога, поиск фондов, в которых может находиться информация о динамике численности населения в селах за 1969-1989 годы. Работа предполагает сплошной просмотр описей и дел определенных фондов и единиц хранения. Изучение документов Территориального органа Федеральной службы государственной статистики по Волгоградской области предполагает накопление статистической информации за 1990-2010 гг. посредством ее копирования. Вся собранная статистическая информация переводится в цифровую форму статистической таблицы Excel, содержащей названия административных районов, сельских поселений, сел, численность населения в них за 1969-
2010 гг., изменения численности населения в них за данный период (см. таблицу). Далее полученная информация перерабатывается методами статистической обработки данных. На ее основе заполняется сводная таблица, в которой отражаются непрерывные переменные, полученные путем точных расчетов.

Tретий этап включает составление тематических карт по каждому выделенному ранее показателю, рабочий масштаб - $1: 500000$.

1. Построение карты «Динамика численности населения сел Волгоградской области». Последующий анализ статистической таблицы дает возможность выделения статистических групп населенных пунктов. Заканчивается процедурой количественного распределения групп. Формируются группы сел по численности населения и динамике показателя его изменения. Численность населения отражается на картограмме размерами условных знаков, количественный показатель динамики - формой условного знака, а интенсивность динамики - цветом. Нанесение условных знаков необходимо ориентировать на точное географическое расположение сел. В заключение выделяются зоны с благоприятным, ограничено благоприятным и неблагоприятным развитием численности населения.

2. Построение картограммы «Территориальные различия условий транспортной до-

Таблиияа

\section{Сводная статистическая таблица данных сел и сельских поселений (фрагмент)}

\begin{tabular}{|c|c|c|c|c|c|c|c|c|}
\hline № & $\begin{array}{c}\text { Название сельских } \\
\text { районов, поселе- } \\
\text { ний, населенных } \\
\text { пунктов }\end{array}$ & $\begin{array}{c}\text { Числен- } \\
\text { ность } \\
\text { сельского } \\
\text { населения } \\
\text { в } 2010 \text { го- } \\
\text { ду в \% к } \\
1969 \text { году }\end{array}$ & $\begin{array}{c}\text { Плот- } \\
\text { ность } \\
\text { сельско- } \\
\text { го насе- } \\
\text { ления в } \\
2010 \text { г., } \\
\text { чел/км² }\end{array}$ & $\begin{array}{c}\text { Группиров- } \\
\text { ка сельских } \\
\text { населенных } \\
\text { пунктов по } \\
\text { численности } \\
\text { населения, } \\
\text { чел. }\end{array}$ & $\begin{array}{c}\text { Группи- } \\
\text { ровка } \\
\text { сель ских } \\
\text { населен- } \\
\text { ных пунк- } \\
\text { тов по } \\
\text { экстрапо- } \\
\text { ляционой } \\
\text { тенденции }\end{array}$ & $\begin{array}{c}\text { Условия } \\
\text { временной } \\
\text { транс- } \\
\text { портной } \\
\text { доступно- } \\
\text { сти г. Вол- } \\
\text { гограда } \\
\text { (часов) }\end{array}$ & $\begin{array}{c}\text { Условия } \\
\text { временной } \\
\text { транс- } \\
\text { портной } \\
\text { доступно- } \\
\text { сти район- } \\
\text { ного цен- } \\
\text { тра, мин }\end{array}$ & $\begin{array}{c}\text { Естест- } \\
\text { венное } \\
\text { плодоро- } \\
\text { дие с/x } \\
\text { угодий в } \\
\text { баллах } \\
\text { бонитета }\end{array}$ \\
\hline 1 & 2 & 3 & 4 & 5 & 6 & 7 & 8 & 9 \\
\hline \multicolumn{9}{|c|}{ Даниловский район } \\
\hline 1 & Атамановское & 50,2 & 3,4 & - & - & - & - & 68 \\
\hline 1.1 & Х. Атамановка & 99,0 & - & До 700 & $\begin{array}{l}\text { умень- } \\
\text { шение }\end{array}$ & 5 & $<45$ & - \\
\hline 1.2 & Х. Кувшинов & 25,8 & - & До 200 & $\begin{array}{l}\text { умень- } \\
\text { шение }\end{array}$ & 5 & $<45$ & - \\
\hline 1.3 & Х. Петруши & 27,2 & - & До 200 & $\begin{array}{l}\text { умень- } \\
\text { шение }\end{array}$ & 5 & $<45$ & - \\
\hline 1.4 & Х. Рогачи & 36,0 & - & До 200 & $\begin{array}{l}\text { умень- } \\
\text { шение }\end{array}$ & 5 & $<45$ & - \\
\hline$\ldots$ & & & & & & & & \\
\hline
\end{tabular}


ступности сельских поселений Волгоградской области» основано на использовании методики изолинейного картографирования посредством проведения изохрон - линий на карте, соединяющих точки с одинаковыми временными показателями транспортной доступности по отношению к основной точке. При этом мы исходим из средней скорости передвижения по дорогам в 60 км/ч. Условия транспортной доступности сельских территорий по отношению к г. Волгограду основано на построении изохрон с опорой на федеральные автодороги, лучами, расходящимися от Волгограда. Строятся изохроны различной временной доступности. Построение изохрон временной транспортной доступности районных центров основано на районной сети дорог с твердым покрытием. Проводятся изолинии 45 минутной транспортной доступности. 30нирование сельских территорий по отношению к г. Волгограду базируется на следующих критериях:

- зона 1,5 часовой доступности - зона непосредственного влияния (зона с наиболее благоприятным потенциалом);

- до 3 часов - зона формирующего влияния (благоприятная зона);

- до 4 часов - зона экономического влияния (ограниченно благоприятная зона);

- свыше 4 часов - зона хозяйственного влияния (неблагоприятная зона).

3. Построение карты «Территориальные различия плотности проживания населения на уровне сельских поселений Волгоградской области». Построение картограммы плотности сельского населения основано на использовании методики наглядного представления статистических данных. Используется методика составления хорохроматических карт, заключающаяся в использовании способа качественного фона, который зависит от интенсивности рассматриваемого процесса. Для выделения статистических групп составляется таблица в Excel, отражающая название сельских поселений, размеры их территории, численность населения в 1969 г. и 2010 г. На основании расчетов вычисляется плотность населения по сельским поселениям. Мы выделили семь статистических групп: 1) с самой высокой плотностью населения; 2) вы- сокой; 3) выше среднего; 4) средней; 5) ниже среднего; 6) низкой; 7) самой низкой. Построенная таким образом карта является важнейшим звеном в выявлении лучших условий для развития сельских территорий.

4. Построение карты «Естественное плодородие сельскохозяйственных земель по сельским поселениям Волгоградской области». При разработке данной карты мы используем методику составления хорохроматических карт. На основании использования статистических данных работы Воробьева А.В. все сельские поселения Волгоградской области по показателю балла бонитета сельскохозяйственных земель (естественного плодородия) мы разделили на три группы: высокий балл, средний балл, низкий балл. Каждая из выявленных статистических групп обозначается способом цветового фона.

Четвертый этап связан с построением комплексной экономико-географической карты «Территориальные различия ресурсного потенциала на сельских территориях Волгоградской области», которая является итогом экономико-географического исследования и служит наглядной базой для оценки благоприятности размещения ресурсного потенциала.

При построении карты используется метод наложения тематически карт, созданных ранее. Сводная карта дополняется формированием базы данных в виде статистической таблицы. В ней отражаются данные о группировке сельских населенных пунктов по численности населения, о группировке по тенденциям (увеличение или уменьшение численности населения), о группировке по условиям транспортной доступности г. Волгограда, о группировке по условиям транспортной доступности районного центра, о группировке по естественному плодородию сельскохозяйственных угодий.

Результаты исследования. Экономико-географический подход в изучении сельских территорий Волгоградской области позволит выявить территориальные различия в:

1) изменениях численности населения по сельским населенным пунктам области;

2) плотности населения по сельским поселениям Волгоградской области; 
3) условиях временной транспортной доступности областного и районных центров для сельских территорий области;

4) естественном плодородии сельскохозяйственных угодий по сельским поселениям области;

5) различиях потенциала развития сельских территорий области на уровне сельских поселений.

Построение комплексной экономико-географической карты «Территориальные различия ресурсного потенциала на сельских территориях Волгоградской области» с использование оверлейных операций позволяет получить интегрированное значение по комплексу показателей. Классификация данных карты позволяет выделить зоны с благоприятными, ограниченно благоприятными и неблагоприятными показателями ресурсного потенциала сельских территорий.

Заключение. В процессе использования картографических методов в изучении системы сельского расселения, ресурсного потенциала сельских территорий создается серия оценочных экономико-географических карт, а также сводные электронные статистические таблицы, отражающие потенциал ресурсов общего пользования по каждому селу области. Итоговым результатом работы является комплексная интегральная оценочная карта ресурсного потенциала сельских территорий. Таким образом, предложенная методика картографического обеспечения экономико-географического исследования сельских территорий, основанная на ключевых экономических показателях, позволяет оценить благоприятность условий хозяйственного развития. Картографическая визуализация базы данных, включающая важнейшие экономические показатели, определяющие потенциал и вектор развития сельских территорий, может быть использована региональными управленческими структурами при принятии решений о развитии сельских территорий.

\section{ПРИМЕЧАНИЕ}

${ }^{1}$ Работа выполнена при финансовой поддержке Администрации Волгоградской области в рамках соглашения о предоставлении из областного бюджета грантов в форме субсидий от 29.11.2019. № 7 .

The reported study was funded by RFBR and the government of Volgograd region according to the research project of 29.11.2019 no. 7 .

\section{СПИСОК ЛИТЕРАТУРЫ}

1. Аляев, В. А. Формирование территориальной структуры хозяйства и транспортной инфраструктуры Волгоградского региона (конец XIX конец XX в.) / В. А. Аляев, М. В. Аляев. - Волгоград : Изд-во ВолГУ, 2018. - 203 с.

2. Аляев, В. А. Транспортная инфраструктура и современная география сел Волгоградской области / В. А. Аляев, М. В. Аляев // Грани познания. - 2014. - № 5 (32). - С. 53-59.

3. Аляев, В. А. Сельское расселение как основа устойчивого развития Волгоградской области / В. А. Аляев, М. В. Аляев // Грани познания. - 2013. № 3 (23). - С. 58-69.

4. Аляев, В. А. Территориальные особенности развития сельского расселения Волгоградской области в конце XX века / В. А. Аляев, Д. А. Семенова // Материалы Первой Междунар. науч.-практ. конф. «Муниципальные образования современных регионов: проблемы исследования, развития и управления в условиях геоэкономической и экономической нестабильности». - Воронеж : Науч. кн., 2016. - C. 12-14.

5. Вишняков, Н. В. Социально-экономическая ретроспектива заселения и освоения района малой излучины реки Дон на примере бассейна реки Большая Голубая / Н. В. Вишняков, Д. А. Семенова // Проблемы региональной экологии. 2016. - № 1. - С. 92-100.

6. Вишняков, Н. В. Изменения в структуре землепользования как следствие демографических трансформаций сельских территорий Волгоградской области / Н. В. Вишняков, Д. А. Семенова // Юг России: экология, развитие. - 2016. - Т. 11. - № 3. C. $165-173$.

7. Галин, Р. А. Расселение сельского населения как фактор развития сельского хозяйства / Р. А. Галин // Экономика и управление : науч.практ. журн. - 2015. - № 5 (127). - С. 28-30.

8. Голд, Дж. Психология и география. Основы поведенческой географии / Дж. Голд. - М. : Прогресс, 1991. - 304 с.

9. Егоров, Д. О. Сельское расселение России: типология территорий по людности сельских населенных пунктов / Д. О. Егоров, В. С. Шурупина // Региональные исследования. - 2018. № 4 (62). - C. 4-16. 
10. Ивлиева, Н. Г. Геоинформационно-картографическое обеспечение исследований пространственно-временных особенностей сельского расселения республики Мордовия / Н. Г. Ивлиева, В. Ф. Манухов // ИнтерКарто. ИнтерГИС. - 2017.Т. 23, № 2. - С. 64-77.

11. Ивлиева, Н. Г. К вопросу построения картографических изображений на основе визуализации атрибутивных данных в ГИС / Н. Г. Ивлиева, В. Ф. Манухов // Геодезия и картография. - 2015. № 2.- С. 32-39.

12. Калашникова, Л. Г. Применение ГИС-технологий в процессе изучения расселения финноугорских народов / Л. Г. Калашникова, В. Ф. Манухов // Научные труды Кубанского государственного технологического университета. - 2014. - № 4. C. $185-187$.

13. Методы географических исследований / П. Тойн, П. Ньюби. - М. : Прогресс, 1977. - Вып. 1 : Экономическая география. - $271 \mathrm{c}$.

14. Руднева, О. С. Структурная эволюция сети сельского расселения в регионах степной зоны России / О. С. Руднева, А. А. Соколов // Russian Economic Bulletin. - 2019. - T. 2. - C. 280-285.

15. Тимонин, С. А. Геоинформационные модели расселения населения и их применение / С. А. Тимонин, В. М. Яблоков // ArcReview.-2011.-№ 3.-C. 7.

16. Хорев, Б. С. Расселение: актуальные проблемы научно-технической политики на современном этапе / Б. С. Хорев // Известия Всесоюзного географического общества. - 1985. - Т. 117. - № 1.

17. Хорев, Б. С. Реконструкция сельского расселения: новый этап научно-технической политики / Б. С. Хорев // Вопросы географии. - 1988. - Т. 132.C. 34 .

18. Alekseev, A. I. Transformation Trends of Russia's Rural Settlement Patterns in the Late Soviet and Post-Soviet Periods (1970-2010) / A. I. Alekseev, S. G. Safronov // Reg. Res. Russ. - 2015. - № 2 (5). P. 193-201.

19. Freeman, L. C. Centrality in Social Networks Conceptual Clarification / L. C. Freeman // Social Networks. - 1978. - № 3 (1). - P. 215-239.

20. Kansky, K.J. Structure of Transportation Networks: Relationships Between Network Geometry and Regional Characteristics / K.J. Kansky. - Chicago : [s.n.], 1963. - $155 \mathrm{p}$.

21. Pitts, F. R. A Graph Theoretic Approach to Historical Geography/ F. R. Pitts // Prof. Geogr. - 1965. № 17 (5). - P. 15-20.

\section{REFERENCES}

1. Alyaev V.A., Alyaev M.V. Formirovanie territorialnoy struktury hozyaystva i transportnoy infrastruktury Volgogradskogo regiona (konets XIX -konets XX v.) [Formation of the Territorial Structure of the Economy and Transport Infrastructure of the Volgograd Region (End of the Nineteenth and End of the Twentieth Century)]. Volgograd, Izd-vo VolGU, 2018, 203 p.

2. Alyaev V.A., Alyaev M.V. Transportnaya infrastruktura i sovremennaya geografiya sel Volgogradskoy oblasti [Transport Infrastructure and Modern Geography of the Villages of the Volgograd Region]. Grani poznaniya, 2014, no. 5 (32), pp. 53-59.

3. Alyaev V.A., Alyaev M.V. Selskoe rasselenie kak osnova ustoychivogo razvitiya Volgogradskoy oblasti [Rural Resettlement as the Basis for Sustainable Development of the Volgograd Region]. Grani poznaniya, 2013, no. 3 (23), pp. 58-69.

4. Alyaev V.A., Semenova D.A. Territorialnye osobennosti razvitiya selskogo rasseleniya Volgogradskoy oblasti v kontse XX veka [Territorial Features of the Development of Rural Settlement of the Volgograd Region at the End of the $\mathrm{XX}^{\text {th }}$ Century]. Materialy Pervoy mezhdunarodnoy nauchnoprakticheskoy konferentsii "Munitsipalnye obrazovaniya sovremennyh regionov: problemy issledovaniya, razvitiya $i$ upravleniya $v$ usloviyah geoekonomicheskoy $\quad i$ ekonomicheskoy nestabilnosti». K 80-letiyu kafedry sotsialnoekonomicheskoy geografii i regionovedeniya. Voronezh, Nauchnaya kniga, 2016, pp. 12-14.

5. Vishnyakov N.V., Semenova D.A. Sotsialnoekonomicheskaya retrospektiva zaseleniya i osvoeniya rayona maloy izluchiny reki Don na primere basseyna reki Bolshaya Golubaya [Socio-Economic Retrospective of the Settlement and Development of the Low Bend of the Don River on the Example of the Great Blue River Basin]. Problemy regionalnoy ekologii, 2016, no. 1, pp. 92-100.

6. Vishnyakov N.V., Semenova D.A. Izmeneniya v strukture zemlepolzovaniya kak sledstvie demograficheskih transformatsiy selskih territoriy Volgogradskoy oblasti [Changes in the Structure of Land Use as a Result of Demographic Transformations of Rural Territories of the Volgograd Region]. Yug Rossii: ekologiya, razvitie, 2016, vol. 11, no. 3, pp. 165-173.

7. Galin R.A. Rasselenie selskogo naseleniya kak faktor razvitiya selskogo hozyaystva [The Settlement of the Rural Population as a Factor in the Development of Agriculture]. Ekonomika i upravlenie: nauchnoprakticheskiy zhurnal, 2015, no. 5 (127), pp. 28-30.

8. Gold Dj. Psihologiya i geografiya. Osnovy povedencheskoy geografii. Moskva, Progress, 1991. $304 \mathrm{p}$.

9. Egorov D.O., Shurupina V.S. Selskoe rasselenie Rossii: tipologiya territoriy po lyudnosti selskih naselennyh punktov [Rural Settlement of Russia: Typology of 
Territories by Population of Rural Settlements]. Regionalnye issledovaniya, 2018, no. 4(62), pp. 4-16.

10. Ivlieva N.G., Manuhov V.F. Geoinformatsionnokartograficheskoe obespechenie issledovaniy prostranstvenno-vremennyh osobennostey selskogo rasseleniya respubliki Mordoviya [GeoinformationCartographic Support for Studies of the Spatio-Temporal Features of Rural Settlement of the Republic of Mordovia]. InterKarto. Inter GIS, 2017, vol. 23, no. 2, pp. 64-77.

11. Ivlieva N.G., Manuhov V.F. K voprosu postroeniya kartograficheskih izobrazheniy na osnove vizualizatsii atributivnyh dannyh v GIS [On the Issue of Constructing Cartographic Images Based on the Visualization of Attribute Data in a GIS]. Geodeziya $i$ kartografiya, 2015, no. 2, pp. 32-39.

12. Kalashnikova L.G., Manuhov V.F. Primenenie GIS-tekhnologiy v protsesse izucheniya rasseleniya finno-ugorskih narodov [Application of GISTechnologies in the Process of Studying the Settlement of Finno-Ugric Peoples]. Nauchnye trudy Kubanskogo gosudarstvennogo tekhnologicheskogo universiteta, 2014, no. 4, pp. 185-187.

13. Metody geograficheskih issledovaniy. T. 1 . Ekonomicheskaya geografiya [Geographic Research Methods. Vol. 1. Economic Geography]. Moscow, Progress, 1977. $271 \mathrm{p}$.

14. Rudneva O.S., Sokolov A.A. Strukturnaya evolyutsiya seti selskogo rasseleniya $\mathrm{v}$ regionah stepnoy zony Rossii [Structural Evolution of the Rural Settlement Network in the Regions of the Steppe Zone of Russia]. Russian Economic Bulletin, 2019, vol. 2, pp. 280-285.

15. Timonin S.A. Geoinformatsionnye modeli rasseleniya naseleniya $\mathrm{i}$ ih primenenie [Geoinformation Models of Population Distribution and Their Application]. ArcReview, 2011, no. 3, pp. 7.

16. Horev B.S. Rasselenie: aktualnye problemy nauchno-tekhnicheskoy politiki na sovremennom etape [Resettlement: Actual Problems of Scientific and Technical Policy at the Present Stage]. Izvestiya Vsesoyuznogo geograficheskogo obshchestva, 1985, Vol. 117, no. 1 .

17. Horev B.S. Rekonstruktsiya selskogo rasseleniya: noviy etap nauchno-tekhnicheskoy politiki [Reconstruction of Rural Settlement: a New Stage of Scientific and Technical Policy]. Voprosy geografii, 1988, vol. 132, pp. 34.

18. Alekseev A.I., Safronov S.G. Transformation Trends of Russia's Rural Settlement Patterns in the Late Soviet and Post-Soviet Periods (1970-2010). Reg. Res. Russ, 2015, no. 2 (5), pp. 193-201.

19. Freeman L.C. Centrality in Social Networks Conceptual Clarification. Social Networks, 1978, no. $3(1)$, pp. 215-239.

20. Kansky K.J. Structure of Transportation Networks: Relationships Between Network Geometry and Regional Characteristics. Chicago, 1963. 155 p.

21. Pitts F.R. A Graph Theoretic Approach to Historical Geography. Prof. Geogr., 1965, no. 17 (5), pp. $15-20$.

\section{Information About the Authors}

Natalya M. Khavanskaya, Candidate of Sciences (Geography), Associate Professor, Department of Geography and Cartography, Volgograd State University, Prosp. Universitetsky, 100, 400062 Volgograd, Russian Federation, khavanskaya@volsu.ru.

Vladimir A. Alyaev, Candidate of Sciences (Geography), Associate Professor, Department of Geography and Cartography, Volgograd State University, Prosp. Universitetsky, 100, 400062 Volgograd, Russian Federation, alyaev@volsu.ru.

Diana A. Semenova, Senior Lecturer, Department of Geography and Cartography, Volgograd State University, Prosp. Universitetsky, 100, 400062 Volgograd, Russian Federation, semenova@volsu.ru.

\section{Информация об авторах}

Наталья Михайловна Хаванская, кандидат географических наук, доцент кафедры географии и картографии, Волгоградский государственный университет, просп. Университетский, 100, 400062 г. Волгоград, Российская Федерация, khavanskaya@volsu.ru.

Владимир Алексеевич Аляев, кандидат географических наук, доцент кафедры географии и картографии, Волгоградский государственный университет, просп. Университетский, 100, 400062 г. Волгоград, Российская Федерация, alyaev@volsu.ru.

Диана Александровна Семенова, старший преподаватель кафедры географии и картографии, Волгоградский государственный университет, просп. Университетский, 100, 400062 г. Волгоград, Российская Федерация, semenova@volsu.ru. 